\title{
Valle Salado de Añana. Un ejemplo internacional de recuperación
}

\begin{abstract}
Fue premio Europa Nostra 2015. La Comisión Europea y Europa Nostra otorgaban este reconocimiento al proyecto de recuperación integral del Valle Salado de Añana (Álava, País Vasco), iniciado hace quince años. En la valoración de esta candidatura, presentada por la Fundación Valle Salado de Añana en la categoría de conservación, se reseñaba la "impresionante magnitud del proyecto, que abarca su paisaje, su arquitectura, su medioambiente, la actividad salinera y sus tradiciones, pero también de forma global al conjunto del territorio mediante iniciativas culturales y turísticas que están siendo motor de desarrollo social, cultural, económico y turístico". Otro de los aspectos destacados ha sido la proyección internacional que ha adquirido el Valle Salado gracias a su recuperación integral y a la exportación de sal de Añana, que se comercializa en más de 25 países.
\end{abstract}

Andoni Erkiaga, Alberto Plata | Fundación Valle Salado de Añana

URL de la contribución <www.iaph.es/revistaph/index.php/revistaph/article/view/3767>

El Valle Salado está ubicado en la localidad de Salinas de Añana (Álava, País Vasco), en el norte de España. La antigua fábrica de sal, con una extensión aproximada de 13 hectáreas, es un paisaje singular y excepcional.

El valor del Valle Salado reside en su insólita arquitectura formada por sucesiones de terrazas escalonadas construidas por el ser humano con piedra seca, madera y arcilla; en las eras de cristalización de la sal y en los cientos de canales de madera de pino que reparten por gravedad el agua salada por todos los rincones mediante un antiguo sistema de reparto comunal. También en el hecho de que los manantiales proporcionan el agua salada de un antiguo mar desaparecido hace 200 millones de años y que el ambiente salino provoca la presencia de una biodiversidad salina que hace que sea un humedal de importancia internacional.

Pero, además, la arquitectura de la sal es única no sólo por sus técnicas constructivas y el impactante paisaje que se crea con la simbiosis de todas ellas, sino porque en el Valle Salado están perfectamente conservados sus más de 6.500 años de historia. Una evolución que hace que convivan en un mismo espacio estructuras de producción con siglos de antigüedad, que fueron desarrolladas para sistemas de producción ya en desuso, con otras que fueron construidas a lo largo del siglo XX. De este modo, las salinas no son un paisaje congelado en el tiempo, sino que son fruto de una compleja evolución desarrollada por los salineros durante miles de años, mediante un largo proceso de ensayo-error basado en su "saber hacer" empírico, con el fin de obtener de la forma más eficiente la mayor cantidad de sal. Corresponde así a la perfecta definición del paisaje como "obra combinada del ser humano y la naturaleza".

Tras milenios de producción ininterrumpida, el auge de las salinas costeras, unido a la revolución del transporte terrestre con la introducción del ferrocarril, provocaron que tanto Añana como el resto de salinas de interior cayeran en un profundo declive. La falta de rentabilidad a partir de finales del siglo XIX provocó que los salineros lucharan con todos los medios para intentar lograr que su producto fuera más competitivo en un mercado que sólo valoraba la cantidad y no la calidad. Durante esta etapa, el Valle Salado se vio amenazado al perder su sostenibilidad. Se construyeron un número desproporcionado de eras, que fueron levantadas sin los medios adecuados y fruto de la urgencia por obtener rápidos beneficios.

Pero el Valle Salado destaca por su resiliencia, su capacidad para absorber impactos negativos, realizar modificaciones, introducir innovaciones y recuperar su vida, apoyado siempre en el conocimiento, las tradiciones y el respeto ecológico. Tras años de lucha por parte de la comunidad salinera, la instituciones públicas iniciaron en el año 2000 la elaboración del Plan Director para la Recuperación Integral del Valle Salado. Tras finalizar 


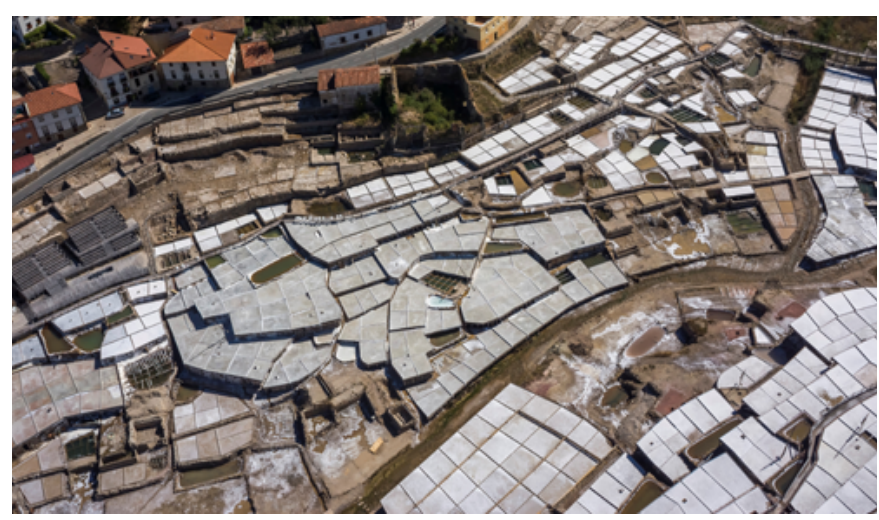

Imagen aérea del Valle Salado | foto Fundación Valle Salado de Añana (Alberto Plata), titular de todas las imágenes de la contribución

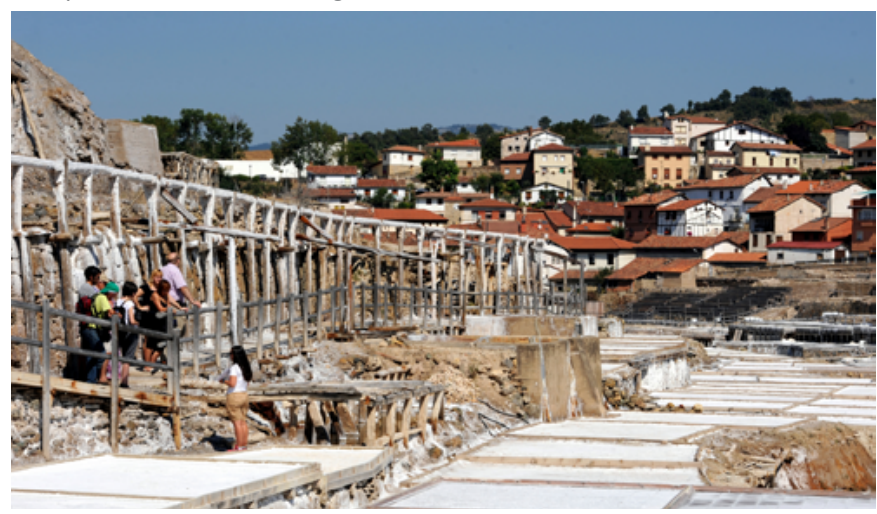

Visitas guiadas por las salinas

su redacción en 2004, las instituciones competentes en patrimonio impulsaron algunas de las directrices que en él se planteaban, siendo una de las más importantes la creación en el año 2009 de la entidad que debía asumir su recuperación, la Fundación Valle Salado de Añana. En esta Fundación sin ánimo de lucro se integra la Diputación Foral de Álava, el Gobierno Vasco, la comunidad de propietarios Gatzagak y el Ayuntamiento de la localidad. Como única propietaria del bien y encargada de su gestión, la Fundación asumió el Plan Director y decidió enfocar el proyecto a recuperar la sostenibilidad del bien y asegurar su integridad volviendo la vista a la historia y rescatando por completo los principios básicos que han regido su producción a lo largo de milenios.

Las labores de recuperación han tenido como objetivo prioritario asegurar su futuro. Pero, además, han supuesto una gran oportunidad para la comunidad local y para el territorio que le rodea, porque todo el proceso

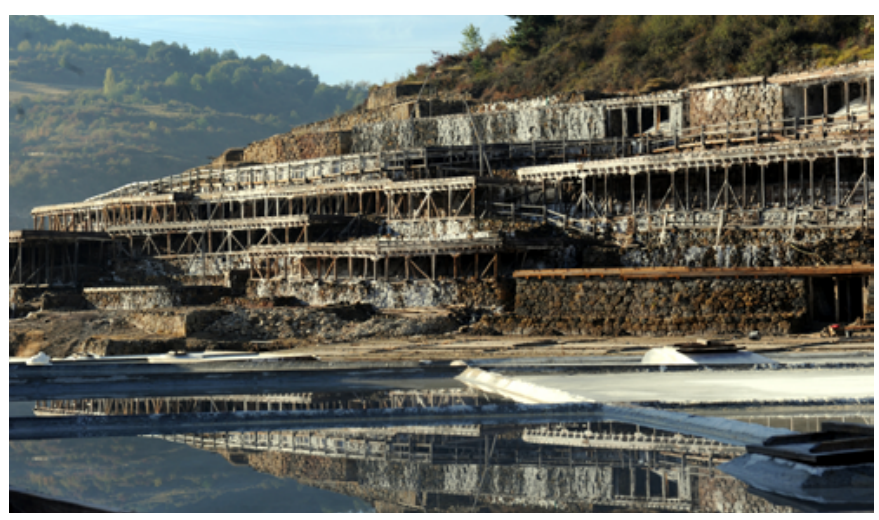

Vista de las terrazas de producción de sal

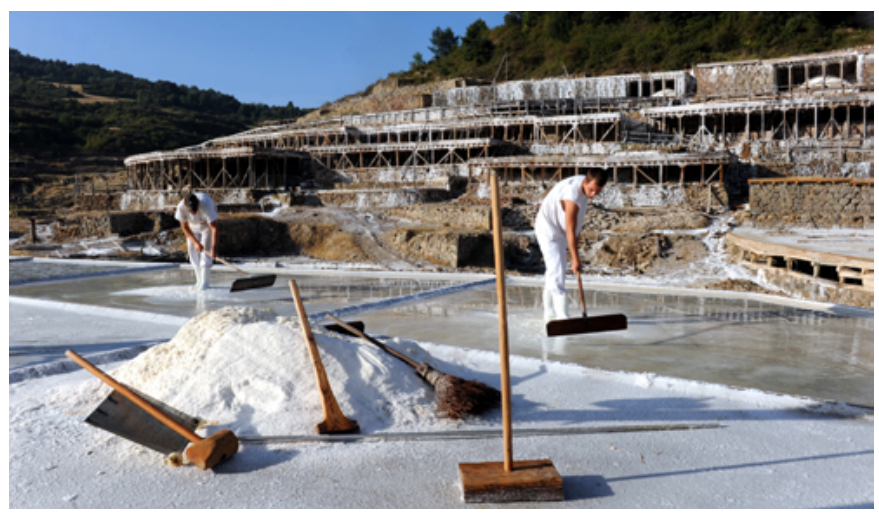

Salineros porduciendo las sal de Añana

de puesta en valor y nuevos usos lo han convertido en un proyecto estratégico y en un potente motor de desarrollo social, cultural, económico y turístico.

La prueba de que el proyecto está bien encaminado es el importante reconocimiento internacional que recibió el Valle Salado en el 2015. Cuando fue galardonado, no sólo con el Premio Unión Europea de Patrimonio Cultural I Premio Europa Nostra 2015, sino con el Grand Prix o Gran Premio del jurado que lo distingue si cabe aún más entre los 28 premiados. De este modo, el Valle Salado añade a sus reconocimientos medioambientales como humedal de la Lista Ramsar de importancia internacional el máximo reconocimiento que se concede en Europa a la recuperación del patrimonio cultural.

\section{Más información}

- www.vallesalado.com 